Disponível em

http://www.anpad.org.br/rac

RAC, Rio de Janeiro, v. 18, n. 3, art. 1, pp. 240-260, Maio/Jun. 2014

doi: http://dx.doi.org/10.1590/1982-7849rac20141085

$(\mathrm{oc})$ EY-No

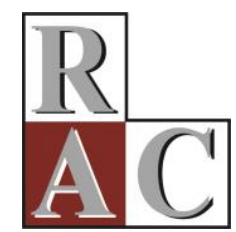

\title{
Relações Raciais e Estudos Organizacionais no Brasil
}

\author{
Race Relations and Organizational Studies in Brazil
}

Alexandre Reis Rosa

E-mail: alexandre.r.rosa@ufes.br

Universidade Federal do Espírito Santo - UFES

Av. Fernando Ferrari, 514, Goiabeiras, 29075-910, Vitória, ES, Brasil.

Artigo recebido em 18.09.2012. Última versão recebida em 16.03.2014. Aprovado em 24.03.2014. 


\title{
Resumo
}

O presente ensaio teórico discute o tema das relações raciais no Brasil e explora suas interfaces com os estudos sobre gestão da diversidade nas organizações. Para tanto, busca problematizar a apropriação que a referida área de estudos tem feito dos trabalhos norte-americanos, colocando em segundo plano - ou até mesmo ignorando os estudos sobre relações raciais desenvolvidos pela antropologia e pela sociologia brasileiras. Essa problematização nos ajuda a perceber que os estudos organizacionais no Brasil têm se colocado de maneira deslocada nesse debate, seja pela suposição de que nossa gestão da diversidade deve seguir parâmetros anglosaxões, seja pelo distanciamento que a área tem mantido dos estudos brasileiros que abordam minorias raciais e sua dinâmica de relações. A parte final do ensaio recupera dois importantes trabalhos produzidos no âmbito dos estudos brasileiros sobre relações raciais e, a partir deles, analisa as possíveis contribuições desse debate para o estudo de organizações brasileiras. Este trabalho termina chamando a atenção dos pesquisadores para a necessidade de se resgatar o debate brasileiro como forma de contextualizar a gestão da diversidade no Brasil.

Palavras-chave: estudos organizacionais; gestão da diversidade; relações raciais.

\begin{abstract}
This theoretical essay discusses the issue of race relations in Brazil and explores its interfaces with studies on diversity management in organizations. Therefore, it seeks to problematize this field's appropriation of American studies, pushing to the background - or even ignoring - studies on race relations developed in Brazilian anthropology and sociology. This questioning helps us realize that organizational studies in Brazil have been displaced in this debate, either by the assumption that our diversity management should follow Anglo-Saxon parameters, or by the distance that the area has maintained from Brazilian studies that address racial minorities and their dynamic relations. The final part of the paper retrieves two important works produced under Brazilian studies on race relations and, from them, examines this debate's contributions to the study of Brazilian organizations. The paper concludes by drawing researchers' attention to the need to rescue the Brazilian debate as a way of contextualizing diversity management in Brazil.
\end{abstract}

Key words: organizational studies; diversity management; race relations. 


\section{Introdução}

"O brasileiro tem preconceito de ter preconceito." Florestan Fernandes (1965)

Os estudos sobre relações raciais conduzidos pela escola paulista nos anos 1950 revelaram, entre outras coisas, que havia certa reserva por parte dos brasileiros em discutir o tema do racismo. Era grande o envolvimento com o discurso da democracia racial produzido nos anos 1930, o que levava muitos brasileiros a acreditarem que não havia racismo no Brasil e, por conta disso, não deveria constar na pauta dos problemas nacionais. Somente após os resultados encontrados por Bastide e Fernandes (1955), o discurso da democracia racial teve suas primeiras fissuras, e o tema do racismo, ainda que de forma incipiente, começou a ocupar espaço cada vez maior nos debates acadêmico, social e político. Outras pesquisas buscaram aprofundar a questão do racismo no Brasil com base nos indicadores de desigualdade social (Hasenbalg, 1979/1995), e os movimentos negros articularam-se de forma mais estruturada e politizada para inserir o racismo no debate nacional (Domingues, 2007).

Ao longo das duas últimas décadas, a questão do racismo tem ganhado crescente importância no debate público em virtude da implementação de cotas raciais em universidades públicas (Alberti \& Pereira, 2006), da criação de órgãos governamentais dedicados ao combate ao racismo (Jaccoud \& Beghin, 2002) e das políticas de ação afirmativa implementadas por empresas brasileiras (Gonçalves, 2006). Em todos os casos, estamos nos referindo a organizações (públicas e privadas) que têm viabilizado a inclusão social dos negros por meio de políticas que visam reduzir desigualdades raciais e, principalmente, romper com o racismo sistêmico que tem impedido a ascensão social dos negros no Brasil (Santos, 2001).

Sabemos que as relações raciais envolvem outros grupos sociais como, por exemplo, indígenas, asiáticos e judeus, sendo este último vítima do antissemitismo após a ascensão do nazi-fascismo na Europa e em outras partes do mundo (Maio, 1993). Apesar das similaridades teóricas que esses diferentes tipos de relações raciais guardam entre si, neste ensaio o foco está nas relações raciais envolvendo negros, brancos e mestiços. A escolha por esse tipo de relação se deu em virtude de os estudos brasileiros sobre raça e racismo terem se ocupado principalmente da questão do negro e dos desdobramentos históricos do período escravocrata para as relações raciais no Brasil e no mundo (Gilroy, 1993; Rocha, 2009).

Sendo assim, considerando o papel das organizações nesse processo, e a dinâmica que as relações raciais entre negros, brancos e mestiços podem assumir no interior delas, podemos formular algumas questões acerca de: (a) Como os estudos organizacionais brasileiros têm se colocado diante dessa temática?; (b) Qual o lugar das relações raciais nos estudos sobre diversidade nas organizações?; e (c) Qual a relevância do contexto sócio-histórico brasileiro para a dinâmica das relações raciais nas organizações brasileiras?

Os estudos recentes sobre diversidade cultural, realizados em contexto brasileiro, revelam importantes lacunas no âmbito dos estudos sobre organizações no Brasil. Essas lacunas resultam basicamente da pouca ênfase que as pesquisas têm dado: (a) aos diversos tipos de minorias nas organizações; (b) às especificidades do contexto organizacional brasileiro diante dessa diversidade; e (c) à efetividade das políticas de promoção da diversidade nas organizações brasileiras. No primeiro caso, Costa e Ferreira (2006) destacam a ênfase nos estudos de gênero e a escassez de pesquisas sobre outras minorias, em particular os estudos sobre pessoas com orientação sexual diversa e sobre raça/etnia. Neste último caso, Vieira e Caldas (2005) também ressaltam a falta de estudos sobre raça e racismo nas organizações brasileiras, e Conceição (2009) aprofunda essa problematização questionando a ausência da raça-etnia como tema de pesquisa nos estudos organizacionais.

Sobre o contexto organizacional brasileiro, Hanashiro e Carvalho (2005) ressaltam a necessidade de uma visão multidisciplinar e de uma apropriação contextualizada às especificidades da cultura brasileira. Alves e Galeão-Silva (2004) também alertam sobre a contextualização e chamam 
atenção para o cuidado em se utilizar modelos de gestão da diversidade desenvolvidos fora do contexto brasileiro, pois a dinâmica das relações raciais no Brasil difere da lógica de outros países, particularmente dos Estados Unidos (EUA), visto como grande exportador de modelos e políticas de igualdade racial.

No caso da efetividade das políticas de promoção da igualdade, a própria inadequação cultural apontada por Alves e Galeão-Silva (2004) deve ser considerada como um limitador do sucesso dessas políticas. Neste sentido, Saraiva e Irigaray (2009) destacam as contradições entre os discursos e as práticas adotadas pelas organizações, tendo nas políticas de diversidade um foco muito mais voltado para o mercado do que para as demandas da sociedade, onde os grupos minoritários se originam e sofrem exclusão. Ainda sobre a efetividade, Myers (2003) aponta para a pouca atenção que as empresas brasileiras dão para o tema do combate ao racismo e, aqueles que atentam para esse tema são, em sua maioria, de origem norte-americana e adotam políticas de promoção da igualdade por exigência das suas matrizes.

Essa pouca ênfase dos estudos organizacionais ao tema das relações raciais decorre, em primeiro lugar, conforme nossa epígrafe, por causa da reserva dos brasileiros em abordar o tema do racismo num país que ainda não resolveu muito bem essa questão, inclusive no campo acadêmico. Em segundo lugar, por causa do flagrante distanciamento dos estudos organizacionais em relação aos estudos sobre relações raciais desenvolvidos no Brasil. Quando analisados em conjunto, esses dois fatores empobrecem nossas análises sobre diversidade nas organizações brasileiras e, justamente por isso, acabam abrindo espaço para os estudos desenvolvidos em outros países, notadamente os EUA, onde a questão racial faz parte da reflexão acadêmica desde os primeiros estudos desenvolvidos pelo afro-americano W. E. B. DuBois, já no final século XIX e início do século XX (Nkomo, 2009).

Com base nessas considerações iniciais, este ensaio teórico tem dois objetivos: o primeiro consiste em problematizar os estudos sobre diversidade que abordam o tema das relações raciais nas organizações sem considerar as especificidades que elas podem assumir no contexto brasileiro. $\mathrm{O}$ segundo objetivo consiste em recuperar o debate brasileiro sobre relações raciais e, a partir dele, refletir sobre as possíveis contribuições para o estudo das organizações brasileiras. Para tanto, foi utilizada a pesquisa bibliográfica. Esse tipo de pesquisa busca utilizar como fonte de dados todo material bibliográfico disponível em livros, artigos, jornais e redes eletrônicas que forneçam conteúdo analítico de interesse da pesquisa. Para Eco (1983), "organizar uma bibliografia significa buscar aquilo cuja existência ainda se ignora" (p. 42). Em termos de resultados, a pesquisa bibliográfica permite: (a) fazer um histórico sobre o tema; (b) atualizar-se sobre o tema escolhido; (c) formular problemas e questões; (d) levantar contradições sobre o tema; e (e) evitar a repetição de trabalhos já realizados (Eco, 1983). Considerando as questões expostas, a pesquisa bibliográfica permite que o tema das relações raciais estabeleça um novo diálogo com os estudos organizacionais ao mesmo tempo em que chama atenção para as possíveis lacunas de pesquisa.

O ensaio está organizado em três grandes blocos. O primeiro faz uma revisão crítica e não exaustiva dos debates sobre raça e diversidade nas organizações, desenvolvido nos estudos norteamericanos a partir da dinâmica de relações raciais deste país. No segundo bloco, é apresentado o debate brasileiro sobre relações raciais e algumas dimensões esquecidas pelos estudos sobre diversidade nas organizações brasileiras. Entre essas dimensões, destacam-se as noções de raça e racismo no Brasil, bem como os diferentes espaços de relações raciais que se caracterizam por ambiguidades que tornam essas relações um fenômeno bastante fluido e indeterminado em nosso contexto social. No terceiro bloco, apresento uma discussão com as possíveis contribuições deste debate para o estudo de organizações brasileiras e chamo atenção para a necessidade de se resgatar o debate brasileiro sobre relações raciais como forma de contextualizar a gestão da diversidade no Brasil. 


\section{Gestão da Diversidade e Relações Raciais nas Organizações: Uma Revisão Crítica}

Quando pensamos na diversidade cultural de países como o Brasil, devemos levar em conta que a presença de múltiplas identidades em nosso território é, sobretudo, um processo histórico. Ao pensarmos nas matrizes de formação do povo brasileiro, temos quatro elementos principais nessa formação: (a) a existência de populações autóctones que já habitavam o continente antes da (b) chegada dos povos europeus durante o período de colonialismo, seguido do (c) tráfico maciço de negros escravizados trazidos da África ocidental e, finalmente, (d) a vinda de imigrantes europeus e asiáticos no final do século XIX e início do século XX, bem como o processo de miscigenação entre todas essas matrizes originais, gerando uma grande população mestiça no país (D. Ribeiro, 1995).

Com exceção dos processos de miscigenação, os EUA tiveram dinâmica similar em sua formação cultural. No entanto, eles continuaram a receber um intenso fluxo de imigrações vindas de todas as partes do mundo e também lidaram de forma distinta com os negros e os povos autóctones, o que acarretou num perfil social diferenciado quando comparado ao perfil brasileiro. Com efeito, os EUA tiveram que enfrentar um paradoxo democrático: promover a igualdade a partir da diferença, com políticas de reconhecimento de estrangeiros, das minorias étnicas e dos seus descendentes. A solução encontrada foi a adoção de políticas de inclusão social que visavam resolver um dilema típico da gestão da diversidade, que é a escolha entre a assimilação e a diferenciação.

No primeiro caso, a tese assimilacionista visa integrar as diferentes culturas fazendo desaparecer suas especificidades, com o abandono de traços distintivos da língua, dos costumes e dos hábitos sociais. A suposição básica do assimilacionismo é que, ao integrar as diferentes culturas, haveria o fim dos conflitos étnico-sociais na medida em que todos compartilhassem de uma única cultura comum (Hartmann \& Gerteis, 2005). O principal problema dessa tese reside no fato de haver a resistência das minorias em se diluírem na cultura dominante, pois se trata de um processo que tende a eliminar identidades coletivas que são fruto da história desses povos, e que não se desfazem facilmente. Como alternativa, a tese da diferenciação, pensada como abordagem multiculturalista, visa reconhecer as diferenças culturais e aceitar a especificidade cultural e social das minorias étnicas, acreditando que indivíduos e grupos podem participar de uma sociedade sem perderem a sua especificidade, mantendo os elementos distintivos das suas culturas (língua, religião, hábitos e costumes). Além disso, a abordagem multiculturalista admite a possibilidade de as minorias lutarem pelo reconhecimento de suas identidades culturais por meio da participação nos processos políticos, com vistas a afirmar sua diferença e obter direitos que eliminem os obstáculos do preconceito e da discriminação (Taylor, 1994).

Na prática, o multiculturalismo refere-se também às estratégias e às políticas adotadas para governar ou administrar problemas de diversidade e multiplicidade gerados pelas sociedades multiculturais (Hall, 2000). Neste sentido, o Estado assume papel importante na construção do modelo multiculturalista, pois cabe a ele o estabelecimento de leis e normas que reconheçam o direito das minorias. O início desse modelo ocorre nos EUA quando, em resposta ao movimento pelos direitos civis nas décadas de 1960 e 70, foi elaborado um conjunto de políticas que buscou incluir os grupos minoritários e reconhecer seu direito à diferença (Kymlicka, 1998). Entre as principais ações do governo americano estava a criação da Affirmative Action (Ação Afirmativa) pelo presidente John F. Kennedy, em 1961, e ampliada pelo presidente Lyndon Johnson em 1964 (Walters, 1995). Essa lei gerou um conjunto de consequências para a sociedade americana em geral, e para as organizações em particular, sendo o ponto de partida para as políticas de diversidade no local de trabalho.

A Ação Afirmativa nos EUA foi uma solução que se desenvolveu no contexto mais amplo de uma política de diversidade não assimilacionista, isto é, multiculturalista, que, por sua vez, desenvolveu-se a partir da própria história das relações raciais naquele país marcado pela Jim Crow. De acordo com Morris (1984), a Jim Crow foi um sistema de dominação tripartite desenhado para controlar os negros politicamente (impedindo o voto e a participação na vida política), economicamente (explorando a força de trabalho sem garantias legais e impedindo o 
empreendedorismo negro) e socialmente (limitando os espaços públicos de convivência entre os brancos e as chamadas colored people). A reação dos negros contra essa situação acarretou o movimento dos direitos civis iniciado e desenvolvido durante todo o século XX, tendo seu ápice nos anos 1960, com a assinatura do Civil Rights Act em 1964, revogando a Jim Crow e garantindo os direitos civis das minorias (Morris, 1999).

A partir de meados da década de 1980, nos EUA, e no final dos anos 1980, no Canadá, a área de gestão de pessoas das empresas iniciou uma intervenção que ficou conhecida como gestão da diversidade ou valorização diversidade. As organizações começaram a ser vistas como espaços multiculturais (Cox, 1991), cujas ações visavam promover melhores condições de trabalho para minorias que sofriam algum tipo de preconceito ou discriminação que dificultava seu acesso às melhores oportunidades no mercado de trabalho. Essa intervenção ficou marcada por três vertentes básicas: a ação afirmativa, a igualdade no emprego e, por fim, a gestão da diversidade (Agócs \& Burr, 1996).

A ação afirmativa se destaca por ser a que praticamente originou as iniciativas de gestão da diversidade (R. Thomas, 1990). Nas organizações, a ação afirmativa também é conhecida como contratação pelos números em virtude do seu foco voltado para o aumento da representação dos grupos designados através da contratação de público-alvo e, em menor grau, da formação e da promoção. Trata-se de uma política destinada a combater diretamente o caráter sistêmico da discriminação que persiste nas políticas e nas práticas cotidianas nas organizações, o que reflete o legado histórico de discriminação que também está presente em outros segmentos da sociedade. Assim, a política de ação afirmativa representa um compromisso para acabar com a discriminação como um valor fundamental que não é subordinado a outros valores (Butler, 1996).

A política de igualdade no emprego foi uma resposta do governo canadense para combater a discriminação e a desvantagem no mercado de trabalho que eram vivenciadas por mulheres, povos indígenas, pessoas com deficiência e minorias raciais. As empresas foram obrigadas a cumprir o Federal Employment Equity Act e o Federal Contractors Program, promulgados em 1986 e revistos em 1995, que os obrigava a recolher e a divulgar dados sobre a representatividade dos seus trabalhadores e, a partir disso, desenvolver planos que incluíssem metas para a contratação e a promoção, bem como medidas para remover barreiras discriminatórias nas políticas e nas práticas de emprego e para acomodar a diversidade na força de trabalho (Agócs \& Burr, 1996). Embora a igualdade no emprego fosse similar à ação afirmativa, ela buscava ir além da contratação pelos números, pois trabalhava também questões relacionadas à percepção dos funcionários a respeito da diversidade, construindo uma visão diferente do papel das minorias nas organizações.

Iniciativas como a ação afirmativa e a igualdade no emprego deram início a um conjunto de políticas que visavam, sobretudo, combater a discriminação e incluir as minorias no mercado de trabalho. A gestão da diversidade, por sua vez, surge no início dos anos 1990 como uma proposta mais ampla, que engloba as anteriores e busca pensar a diversidade também como uma vantagem para as organizações (Gilbert, Stead, \& Ivancevich, 1999). Para R. Thomas (1990), a gestão da diversidade se diferencia das iniciativas anteriores porque adota um enfoque holístico para criar um ambiente organizacional que possibilite a todos o pleno desenvolvimento de seu potencial na realização dos objetivos da empresa. Entre as vantagens da gestão da diversidade, Cox e Blake (1991) destacam que a gestão da diversidade reduz o turnover e o absenteísmo; sensibiliza a empresa para novas culturas que formam o mercado; aumenta a criatividade e a inovação da empresa; aumenta a capacidade de resolução de problemas na empresa; e aumenta a flexibilidade da gestão.

Neste sentido, D. Thomas e Ely (1996) destacam que, ao se formar uma força de trabalho heterogênea, com diversas culturas, isso permite acessar diferentes segmentos de consumidores, compreendendo melhor suas demandas. Cox (1993) argumenta que a gestão da diversidade implica em planejar e executar sistemas e práticas organizacionais de modo a maximizar as vantagens potenciais da diversidade e minimizar suas desvantagens. Entre essas práticas destacam-se, por exemplo, políticas de recursos humanos com foco nas minorias, adaptando processos de recrutamento e seleção, treinamento e desenvolvimento, remuneração, plano de carreira e avaliação do desempenho; criação 
de formas de tutoria (mentoring) para acompanhar o desenvolvimento dos diversos grupos; grupos de discussão (diversity councils) para elaborar e aprimorar as políticas; compensações específicas para valorização da diversidade; e o estabelecimento de procedimentos para garantir a lisura dos processos de valorização da diversidade na empresa (Kalev, Kelly, \& Dobbin, 2006).

Embora todas essas pesquisas abordem diferentes experiências de inclusão racial, e apontem as vantagens para as organizações norte-americanas, ao fazer um balanço crítico sobre os estudos raciais no campo da gestão e da organização, Cox e Nkomo (1990) identificam que eles se limitam aos aspectos demográficos e performáticos dessas práticas, com testes de validação que focam sobretudo satisfação, atitudes e motivação dos funcionários. Estes, na maioria dos casos, são vistos com base em estereótipos produzidos a partir da dicotomia brancos e negros, negligenciando a presença de outros grupos étnicos nas organizações. Por fim, as pesquisas deixam também de abordar um ponto crítico nos estudos raciais que é a presença ou não de preconceito e discriminação nas relações interpessoais ou intergrupais na organização. Essas limitações são analisadas em outro trabalho de Nkomo (1992) que atribui esse silêncio ao fato de a maioria dos pesquisadores serem brancos, o que os leva a reproduzir uma lógica eurocentrista que ignora a existência do Outro e tende a assumir as organizações como espaços racialmente neutros. Diante dos limites identificados, a autora propõe que os estudos sobre raça nas organizações devem incluir outras narrativas sobre o tema, não focar apenas nos aspectos performáticos das relações raciais e considerar também a dimensão do poder e o contexto histórico que perpassam essas relações (Nkomo, 1992).

Apesar de levantarem importantes questões sobre os estudos raciais nas organizações, Cox e Nkomo (1990) e Nkomo (1992) o fazem a partir de um lugar específico, que é o de pesquisadores inseridos no contexto de relações raciais norte-americano, o que nos coloca diante de argumentos que guardam em si particularidades daquele país que não são compartilhadas por outros contextos raciais. Ainda que em outro balanço crítico feita na área (Zanoni, Janssens, Benschop, \& Nkomo, 2010), publicado duas décadas depois, a autora, em coautoria com outras pesquisadoras, reconheça a necessidade de se considerar o contexto socio-histórico dos diferentes países fora dos EUA, continuamos a conduzir pesquisas no Brasil com base nos parâmetros da produção norte-americana (São Paulo, 2010) e, principalmente, a propor medidas e a mensurar a diversidade nas organizações brasileiras com base nesses mesmos parâmetros (Instituto Ethos, 2010a, 2010b).

A seguir, apresentar-se-á uma breve revisão dos estudos sobre relações raciais no Brasil e, com base neles, serão exploradas possíveis contribuições para os estudos organizacionais como alternativa ao referencial norte-americano sobre race in organizations.

\section{Relações Raciais no Debate Brasileiro}

Um dos temas mais relevantes para as ciências sociais no Brasil, ao longo do século $X X$ - e que agora volta com força no século XXI - é o das relações raciais (Guimarães, 1999). A própria origem do pensamento científico no Brasil está relacionada a esse tema, quando, na década de 1870, diversas pesquisas buscavam comprovar a inferioridade do negro e pensar numa solução para o problema da degeneração que poderia ser provocada pelo intenso processo de miscigenação (Maio, 1999; Schwarcz, 1993). De lá para cá, o tema sofreu uma série de inflexões, mas continua sendo um desafio para os pesquisadores e um tabu para uma sociedade que se nega a debatê-lo (Fernandes, 1965). Nos próximos itens, será apresentado um resgate histórico e conceitual do tema, buscando, com isso, contextualizar a questão racial para depois pensá-la a partir da realidade brasileira.

\section{Do racismo científico à democracia racial e depois}

Para Hall (1999, p. 62), 
a raça é uma categoria discursiva e não uma categoria biológica. Isto é, ela é uma categoria organizadora daquelas formas de falar, daqueles sistemas de representação e práticas sociais que utilizam um conjunto frouxo, frequentemente pouco específico, de diferenças em termos de características físicas e corporais - cor da pele, textura do cabelo, características físicas e corporais, etc. - como marcas simbólicas, a fim de diferenciar socialmente um grupo do outro.

Historicamente, segundo Quijano (2000), foi a partir destas diferenças raciais que se produziram identidades sociais capazes de classificar (ou rotular) quem era o dominante e quem era o dominado. Ao se produzir tipologias como índio, negro, mestiço, produzem-se também, por contraste, as figuras do português, do francês, e do britânico, que num segundo momento passam a se agrupar nas figuras de africanos, asiáticos, ameríndios e europeus, que, até então, indicavam apenas a localização geográfica desses sujeitos. Contudo, os desdobramentos da descoberta fizeram com que tais diferenças assumissem uma conotação racial, estabelecendo hierarquias e papéis sociais correspondentes a cada uma delas.

Assim, o período colonial foi crucial no desenvolvimento dos estudos sobre raça que buscavam compreendê-la com base na biologia. Isto é, havia diferenças naturais que explicavam a superioridade ou a inferioridade das diversas raças humanas (Banton, 1979). Na experiência brasileira, o diagnóstico científico sobre as raças surge com o interesse da Coroa Portuguesa em conhecer o potencial de recursos a ser explorado na colônia (Szmerecsányi, 1985). Os encarregados de fazer esse trabalho eram os chamados naturalistas viajantes, que utilizavam métodos científicos para catalogar minerais, vegetais e animais. Sendo que "entre os animais estavam incluídos os homens, dos quais o comportamento e a língua eram características a ser classificadas e comparadas" (Leite, 1995, p. 8).

Além do vínculo com as Cortes mercantilistas, os naturalistas viajantes estavam também ligados a sociedades científicas, cujos estudos resultaram em importantes inovações na área, que influenciaram todo o século XIX e início do século XX. Entre elas estava o conceito de raças humanas, gestado a partir de uma antropologia física que se ocupou por décadas em classificar grupos humanos, com o intuito de hierarquizá-los de modo a legitimar a expansão colonial das potências europeias, que se legitimava, nestes estudos, a partir de uma suposta superioridade "natural" dos povos mais aptos sobre os menos aptos. Assim, a ideia de raça, como justificativa biológica da desigualdade entre os povos, também chegaria aos trópicos por meio dos chamados homens de scientia e da institucionalização das ciências no Brasil a partir da segunda metade do século XIX (Schwarcz, 1993).

O que os estudos raciais da época tinham em comum era a defesa científica da superioridade do homem branco europeu sobre as demais raças que habitavam os extensos domínios coloniais em África, Ásia e Américas (Skidmore, 1989). O desafio desses homens de scientia consistia em adaptar tais estudos ao contexto racial do país, atualizando o que combinava e descartando o que fosse problemático para a construção de um argumento local. Neste sentido, as adaptações realizadas pelos cientistas brasileiros oscilaram entre a segregação e a extinção (Hofbauer, 2006). A tese segregacionista era defendida por aqueles que percebiam a miscigenação como uma ameaça que poderia levar o povo brasileiro à degeneração, impossibilitando sua própria constituição como nação. Entre eles, estava o médico Raimundo Nina Rodrigues, que, apoiado em teorias evolucionistas, percebia o negro como uma raça em estágio evolutivo inferior ao branco (Nina Rodrigues, 1935). Em outra direção, a tese da extinção via na miscigenação uma oportunidade de regenerar o povo brasileiro por meio de um processo de branqueamento paulatino, que levaria ao desaparecimento progressivo dos negros e mestiços de pele escura. Aqui ganha destaque o trabalho do médico João Baptista Lacerda que, também sob a ótica evolucionista, concordava com o atraso das raças inferiores apontado por Nina Rodrigues, porém vislumbrava nos cruzamentos inter-raciais uma possibilidade de reverter esse quadro. Assumia o mestiço como uma categoria transitória em vias de se regenerar através de sucessivos cruzamentos com a raça superior, ou seja, os brancos (Lacerda, 1912).

Nas duas adaptações, seja a favor ou contra a miscigenação, há uma percepção negativa em relação à raça negra. Para o racismo científico o mestiço encerra "os defeitos e taras transmitidos pela herança biológica. A apatia, a imprevidência, o desequilíbrio moral e intelectual, a inconsistência seriam dessa forma qualidades naturais do elemento brasileiro" (Ortiz, 1985, p. 21). O que revela não 
apenas como as elites do final do século XIX e início do XX interpretavam as relações raciais, mas, sobretudo como elas contribuíam para a manutenção de um sistema hierarquicamente dividido, que mantinha praticamente intacta a condição subalterna dos negros e dos mestiços de pele escura na sociedade. O contraponto ocorre algumas décadas depois com a publicação, em 1933, de Casa Grande \& Senzala, em que tanto a ameaça de degeneração quanto a oportunidade do branqueamento são repensados por Gilberto Freyre (1933/2006), que atribui à miscigenação um caráter positivo, colocando-a como a possibilidade de criar um sujeito adaptado aos trópicos. Contudo, ao fazer isso, acaba por assumir uma posição ambígua em relação à situação dos negros no Brasil, pois se, de um lado, o autor denuncia o maniqueísmo do racismo científico, de outro, constrói a imagem de um país livre de tensões raciais.

Esta imagem foi o ponto de partida de uma política internacional de combate ao racismo a ser elaborada pela Organização das Nações Unidas para a Educação, Ciência e Cultura (Unesco), que via na experiência brasileira um modelo de relações raciais a ser estudado e compreendido como solução aos contextos onde havia tensões e conflitos raciais (Maio, 1999). Entretanto, foi justamente a partir desta iniciativa, denominada de Projeto Unesco, que a tese freyreana enfrentou suas maiores críticas, gerando, com isso, novas interpretações sobre a questão racial no Brasil. Assim, o projeto Unesco contribuiu para a formação de dois polos de argumentação: o da democracia racial e o da desigualdade racial. Nos diferentes estudos, focados em diferentes dimensões do racismo, uma parte dos pesquisadores buscava provar a existência de um Brasil miscigenado, onde as diferenças se davam pela via econômica e não pela racial, ao passo que outros, preocuparam-se em validar empiricamente o fato de que estas desigualdades eram também econômicas, mas, sobretudo, raciais. O que resultou em diferentes paradigmas de interpretação sobre o que é o racismo no Brasil e como ele deve ser combatido.

\section{Os paradigmas de interpretação das relações raciais}

Ao longo dos anos que sucederam o projeto Unesco, formaram-se algumas abordagens em torno de seus resultados. Segundo Motta (2000, p. 152), "é possível reconhecer três paradigmas principais no estudo das relações raciais no Brasil, relacionados, respectivamente, aos trabalhos de Gilberto Freyre, Florestan Fernandes e Carlos Hasenbalg". Ao destacar estes três autores, a discussão subsequente se faz em torno deles e dos fundamentos que cada um defendeu no debate acadêmico sobre relações raciais no Brasil.

O paradigma da morenidade forma-se a partir de um alinhamento entre as ideias de Gilberto Freyre e dos norte-americanos Marvin Harris e Carl Degler, que construíram, em paralelo, argumentos muitos parecidos sobre a singularidade das relações raciais no Brasil. Motta (2000) faz uma leitura justaposta destes autores, tomando como ponto de interseção a categoria moreno, "cuja ambiguidade mostraria a reduzida importância das classificações raciais na sociedade brasileira" (Motta, 2000, p. 117). Com efeito, para os três autores, não fazia sentido impor categorias dicotômicas (brancos/não brancos) ou tricotômicas (brancos/mestiços/negros), aos moldes norte-americanos, num país onde a desigualdade e a subalternidade eram determinadas muito mais por fatores relacionados à classe social, à religião e à demografia do que pela raça. No caso específico de Degler (1976), o moreno traduzia-se na dupla negação do nem preto, nem branco. Isto é, uma saída de emergência que possibilitava um reconhecimento social do mestiço no Brasil. Em resumo, o que estava em jogo era o não reconhecimento da raça como fator de desigualdade entre as pessoas que, aos olhos deles, não viviam num paraíso racial, mas gozavam de um status meta-racial pelo fato de serem morenos.

No segundo paradigma, Motta (2000) apresenta a leitura que Florestan Fernandes faz em oposição à interpretação freyreana. Na leitura da escola paulista, o racismo estava articulado com a noção de classe social, pois, historicamente, ambos se reproduzem a partir de um sistema econômico que tende a colocar os negros numa situação de desvantagem nas relações de produção. Ou seja, para Fernandes, o racismo seria um resíduo histórico da ordem escravocrata que se mantém nos dias atuais por conta da "sobrevivência de ideologias ou atitudes que, no passado, decorreram de relações de classe e subsistem no presente por força de certa inércia cultural" (Motta, 2000, p. 125). Assim, como 
não há um recorte puramente de classe, já que o preconceito de classe se articula com o de raça, a explicação de Fernandes acaba se afastando do paradigma da morenidade à medida que reconhece a desigualdade entre negros e brancos na ordem competitiva do capitalismo como um efeito também da raça.

O terceiro paradigma pode ser caracterizado a partir do questionamento que Hasenbalg (1979/1995) faz ao caráter residual do racismo na reflexão paulista. Para o autor, o racismo não se reproduz apenas pela sobrevivência de padrões arcaicos e tradicionais das relações entre grupos, mas, sobretudo pelas vantagens que o branco obtém com a desqualificação competitiva dos não brancos. Em sua análise, a competição se torna desigual porque existem práticas discriminatórias sutis e mecanismos racistas mais gerais que acabam gerando maiores oportunidades para os brancos, com ganhos ocupacionais e de renda superiores. Assim, se o processo de competição social é injusto com os não brancos, então a mobilização de classe perde força diante da mobilização racial. Afinal, diferente de Fernandes, o componente racial não é um coadjuvante da classe, mas um elemento central nas desigualdades entre brancos e não brancos na ordem capitalista.

Nesse último ponto, é importante notar que Hasenbalg, ao se referir aos grupos em disputa, não distingue os morenos dos negros. Trata-os como sendo não brancos, pois, para ele, o mestiço sofre as mesmas desvantagens que o negro quando em competição com o branco. Com efeito, a tese de Degler (1976) da saída de emergência do mulato perde sua validade ao ser confrontada com os resultados encontrados por Hasenbalg (1979/1995) em sua pesquisa sobre as desigualdades entre brancos e não brancos. Será justamente nessa posição contrária à morenidade que o autor se aproxima de Fernandes, pois ambos combatem, por caminhos diferentes, o mesmo paradigma. Porém, quando o autor elabora um recorte exclusivamente racial em sua análise, agrupando negros e mestiços numa categoria única de não brancos, opera uma lógica que será o principal fundamento dos estudos sob a perspectiva racialista. Isto é, os estudos que privilegiam a raça como uma categoria separada da classe para análise das relações raciais.

Todavia, importante ressaltar que a construção da categoria raça com base na descendência - ou seja, todos os mestiços vistos como afro-descedentes - segue o princípio da hipodescendência (mais conhecido como one drop rule), que é a base para a construção da identidade afro-descendente. Tratase de uma regra criada pelos escravocratas do sul dos EUA para definir que todos os filhos de relações interétnicas, especificamente entre brancos e pretos, seriam automaticamente pretos. Nessa situação, a pessoa herdaria ad infinitum a identidade social do(a) progenitor(a) menos prestigiado(a). Com isso, os mestiços ficariam impedidos de reivindicar para si a identidade branca e a cultura do mundo branco, tampouco integrar-se a ele nas relações sociais. Ficariam confinados ao mundo dos pretos, com todos os prejuízos que esse mundo poderia acarretar na época da Jim Crow (Hollinger, 2003).

\section{Dimensões Esquecidas de um Debate que (Ainda) Não Foi Feito}

As possibilidades abertas pelos paradigmas de interpretação das relações raciais nos revelam um campo de estudos com diferentes perspectivas de análise que ajudam a compreender algumas dimensões esquecidas ou ignoradas pelos estudos organizacionais. Ao confrontar três olhares sobre a condição do negro no Brasil, com: (a) a tese da morenidade e a miscigenação como traço fundamental (Degler, 1976; Freyre, 2006); a (b) articulação da raça com a noção de classe e a dimensão econômica do preconceito (Fernandes, 1965); e, por fim, a (c) conexão entre negros e mestiços como um grupo de não brancos expostos aos mesmo mecanismos de exclusão (Hasenbalg, 1979/1995), o debate nos mostra que há diferentes possibilidades de análise para as dimensões de raça, racismo e relações raciais no contexto brasileiro.

A seguir, serão apresentados dois estudos sobre essas dimensões e uma breve discussão sobre como eles podem contribuir para um diálogo mais estreito entre os estudos raciais e os estudos organizacionais brasileiros. 


\section{O negro e o racismo no Brasil: de marca e de origem}

Quando os primeiros resultados do projeto Unesco foram divulgados, constatou-se que o Brasil não era uma excepcionalidade em termos de relações raciais - conforme acreditava a Unesco - pois aqui também havia preconceito e discriminação contra os negros, porém não na mesma intensidade que os EUA - visto como locus de tensão e segregação racial.

Para compreender melhor as diferenças entre o racismo brasileiro e o norte-americano, o sociólogo Oracy Nogueira (2007) desenvolveu o conceito de preconceito de marca, que se referia à aparência do negro e às suas características físicas, em contraste ao conceito de preconceito de origem, que se referia à ascendência do negro e ao seu vínculo ao grupo étnico com alguma ancestralidade africana. Assim, o autor desenvolve uma crítica aos modelos teóricos que diferenciavam os dois países apenas em termos de intensidade do preconceito, sem, contudo, qualificálo. Para tanto, elabora doze proposições que tratam dessas diferenças entre os dois países, conforme a Tabela 1.

Tabela 1

Diferenças Entre o Preconceito Racial no Brasil e nos EUA

\begin{tabular}{l} 
Proposições \\
\hline 1. Quanto ao modo de atuar \\
2. Quanto à definição de membro \\
do grupo discriminador e do \\
grupo discriminado
\end{tabular}

\section{Quanto à carga afetiva}

\section{Quanto ao efeito sobre as relações interpessoais}

\section{Quanto à ideologia}

\section{Quanto à distinção entre} diferentes minorias

\section{Quanto à etiqueta} discriminado

\section{Preconceito de marca (Brasil) Preconceito de origem (EUA)}

Determina uma preterição de acordo Determina uma exclusão com a posição social e a relação com o grupo discriminador. incondicional dos membros do grupo discriminado.

Classifica de acordo com o fenótipo ou aparência racial, podendo variar bastante no caso dos mestiços.

Tende a ser mais intelectivo e estético, pois a atribuição de inferioridade depende dos traços negroides e não se traduz em ódio racial, mas em tratamento diferenciado.

As relações pessoais, de amizade e admiração cruzam facilmente as fronteiras de cor.

A ideologia é, ao mesmo tempo, assimilacionista e miscigenacionista.

A cultura prevalece sobre a raça, ou seja, as minorias menos endogâmicas e menos etnocêntricas são favorecidas.

A ênfase está no controle do
comportamento de indivíduos do
grupo discriminador, de modo a
evitar a susceptibilização ou
humilhação de indivíduos do grupo
discriminado.

A consciência da discriminação tende a ser intermitente.
Classifica de acordo com o genótipo, seja qual for sua aparência e qualquer que seja o grau de mestiçagem.

Tende a ser mais emocional e mais integral, pois a atribuição de inferioridade é irrefletida e traz consigo o ódio racial que justifica a segregação entre os grupos.

As relações entre indivíduos do grupo discriminador e do grupo discriminado são severamente restringidas por tabus e sanções.

A ideologia é segregacionista e racista.

Prevalece o oposto, ou seja, há maior tolerância para com as minorias mais endogâmicas e mais etnocêntricas.

A ênfase está no controle do comportamento de membros do grupo discriminado, de modo a conter a agressividade contra os elementos do grupo discriminador.

A consciência da discriminação tende a ser contínua, obsedante. 
Tabela 1 (continuação)

\begin{tabular}{lll}
\hline Proposições & Preconceito de marca (Brasil) & Preconceito de origem (EUA) \\
\hline $\begin{array}{l}\text { 9. Quanto à reação do grupo } \\
\text { discriminado }\end{array}$ & $\begin{array}{l}\text { A reação tende a ser individual, } \\
\text { procurando o indivíduo } \\
\text { "compensar" suas marcas pela } \\
\text { ostentação de aptidões e }\end{array}$ & $\begin{array}{l}\text { A reação tende a ser coletiva, pelo } \\
\text { reforço da solidariedade grupal, pela } \\
\text { redefinição estética e etc. }\end{array}$
\end{tabular}

$$
\begin{aligned}
& \text { características que impliquem } \\
& \text { aprovação social. }
\end{aligned}
$$

\section{Quanto ao efeito da variação proporcional do contingente minoritário}

\section{Quanto à estrutura social}

12. Quanto ao tipo de movimento político a que inspira
A tendência é se atenuar nos pontos em que há maior proporção de indivíduos do grupo discriminado.

A probabilidade de ascensão social está na razão inversa da intensidade das marcas de que o indivíduo é portador, ficando o preconceito de raça disfarçado sob o de classe, com o qual tende a coincidir.

A luta do grupo discriminado tende a se confundir com a luta de classes.
A tendência é se apresentar sob forma agravada, nos pontos em que o grupo discriminado se torna mais numeroso.

O grupo discriminador e o discriminado permanecem rigidamente separados um do outro, em status, como se fossem duas sociedades paralelas, em simbiose, porém irredutíveis uma à outra.

O grupo discriminado atua como uma "minoria nacional" coesa e, portanto, capaz e propensa à ação conjugada.

Nota. Fonte: Adaptado de Nogueira, O. (2007). Preconceito racial de marca e preconceito racial de origem: sugestão de um quadro de referência para a interpretação do material sobre relações raciais no Brasil. Tempo Social, 19(1), 287-308. doi: $10.1590 /$ S0103-20702007000100015

Ao comparar a situação racial nos EUA e no Brasil, Nogueira (2007) constata dois tipos diferentes: "um em que o preconceito racial é manifesto e insofismável e outro em que o próprio reconhecimento do preconceito tem dado margem a uma controvérsia difícil de se superar" (p. 291). Isto é, nos EUA há um sentimento arraigado de inferioridade dos grupos discriminados que impede concessões nas relações raciais, produzindo posições estanques com o grupo discriminador. No Brasil, o tema se torna ambíguo e difícil de ser determinado devido à fluidez com que se apresenta nas diferentes ocasiões. Apesar de cumprir o objetivo de qualificar a situação racial nos dois países de maneira detalhada e com exemplos que corroboram as proposições, o autor faz uma ressalva dizendo que tais proposições agem "como indicativas de tendências e como hipóteses a serem aferidas, seja através de novas pesquisas de campo, seja através da reconsideração de dados já disponíveis" (Nogueira, 2007, p. 292). Neste sentido, vale destacar que a avaliação de Nogueira (2007) se refere à década de 1950, período em que os EUA estavam imersos nas atrocidades da Jim Crow, e o Brasil ainda ensaiava os primeiros passos na luta antirracista, o que nos obriga a atualizar algumas proposições. Porém, várias outras ainda preservam sua validade e guardam forte correspondência com os paradigmas de estudos das relações raciais.

A própria formulação da marca e da origem nos coloca diante da questão sobre quem é negro no Brasil. Se nos EUA essa identidade negra está ligada à ascendência, então lá o mestiço não existe e todos que possuem uma gota de sangue negro, são negros. Já no Brasil, a aparência física, com todas as variações que ela pode assumir (formato dos lábios e do nariz, textura do cabelo, cor da pele, etc.), faz com que a identidade negra seja bastante fluida em virtude do hibridismo que autoriza a identidade mestiça, ou seja, a existência do moreno. Como no Brasil não há separações estanques entre as raças, as quais, nos EUA, criam sociedade paralelas (mundo dos negros e mundo dos brancos), aqui a dinâmica das relações sociais também se torna igualmente fluida, e a questão de classe se funde à questão racial. Assim, se nos EUA a mobilização social com base na raça se torna possível em virtude da própria estrutura social, no Brasil ela enfrenta dificuldades devido à fluidez com que essa categoria é interpretada. O que não significa dizer que aqui não haja preconceito e discriminação contra os negros. Afinal, se nos EUA o preconceito e a discriminação podem ser facilmente identificados e 
combatidos, no Brasil eles ocorrem de forma disfarçada devido ao caráter contingencial que marca a dinâmica das relações raciais.

Em síntese, a discussão apresentada até o momento nos mostra que, sendo a raça uma categoria discursiva, ela pode representar múltiplas formas de diferença entre os grupos humanos. Na experiência brasileira, a cor teve maior importância nas diferenças entre os grupos ao longo da história. Ou seja, para os brasileiros, a cor da pele representa uma marca que identifica quem é e quem não é negro no Brasil. Diferente dos EUA, que privilegiou a origem étnica por meio da hipodescendência.

\section{As relações raciais no Brasil: áreas duras, moles e espaços negros}

Se no Brasil predomina o preconceito de marca, isto é, com base na cor da pele, então é possível perguntar "como as pessoas reinterpretam e usam a cor no cotidiano das relações raciais?" (Sansone, 1996, p. 169). Preocupado em responder essa questão, o antropólogo Lívio Sansone (1996) realizou um estudo na Região Metropolitana de Salvador, no Estado da Bahia, com o intuito de elaborar um esquema de classificação racial da vida cotidiana, em contraste aos esquemas formalmente em uso, como o do governo (brancos, pretos, pardos, amarelos e indígenas), o da fábula das três raças (brancos, negros e índios) e o esquema bipolar proposto pelo movimento negro moderno, inspirado nos EUA (brancos e negros).

Os resultados mostram cerca de 37 categorias de cor/raça, com a predominância de oito delas (cerca de 91\% dos informantes) dispostos em categorias que vão desde branco, passando por mulato, moreno, moreno claro, moreno escuro, escuro, preto e negro. Além disso, a pesquisa mostrou que há uma variação das respostas de acordo com certos fatores, e que a fluidez entre as categorias encontradas ocorre de forma contingencial, pois dependem do tempo, dos laços afetivos, da renda ou classe social, da idade e, principalmente, do lugar. Conforme mostra a Tabela 2.

Tabela 2

Fatores Contingenciais e Percepções sobre Raça e Racismo

\begin{tabular}{lll}
\hline Fatores contingenciais & Percepções sobre raça e racismo \\
\hline Tempo & De dia & $\begin{array}{l}\text { Durante o dia, quando as pessoas estão na luta, a tendência é minimizar } \\
\text { diferenças de cor, evita-se falar em negro. Se necessário, fala-se em moreno, } \\
\text { escuro ou pardo. }\end{array}$ \\
\cline { 2 - 3 } & De noite & $\begin{array}{l}\text { À noite e nos fins de semana, quando o assunto é descansar e curtir, os termos } \\
\text { raciais são utilizados como expressão de amizade (meu preto) ou veemência } \\
\text { (branquelo). }\end{array}$ \\
\hline Laços afetivos & Forte & $\begin{array}{l}\text { Quando há proximidade por amizade, parentesco ou respeito, utilizam-se termos } \\
\text { como moreno no lugar de preto e misturada no lugar branca ou negra. }\end{array}$ \\
\cline { 2 - 3 } & Fraco & $\begin{array}{l}\text { Quando não há proximidade, utiliza-se escuro ou escurinho, ou no caso de } \\
\text { pessoas mais escuras, preto ou negão para sublinhar o status baixo. }\end{array}$ \\
\hline $\begin{array}{l}\text { Renda ou } \\
\text { Classe social }\end{array}$ & Alta & $\begin{array}{l}\text { As pessoas que ocupam posições de status (profissionais liberais, autoridades, } \\
\text { etc.) tendem a ser vistas como mais claras, tais como morenas ou mesmo } \\
\text { brancas. }\end{array}$ \\
\cline { 2 - 3 } & Baixa & $\begin{array}{l}\text { As pessoas que ocupam posições subalternas (serventes, pedreiros, garis, etc.) } \\
\text { tendem a ser vistas como mais escuras, tais escurinho, pretinho ou mesmo negro. }\end{array}$ \\
\hline
\end{tabular}


Tabela 2 (continuação)

\begin{tabular}{lll}
\hline Fatores contingenciais & Percepções sobre raça e racismo \\
\hline Idade & Velho & $\begin{array}{l}\text { Entre as pessoas mais velhas (acima de } 50 \text { anos), predomina o discurso da } \\
\text { mestiçagem, com uso mais amplo das categorias flutuantes como moreno claro e } \\
\text { moreno escuro. }\end{array}$ \\
\cline { 2 - 4 } & Jovem & $\begin{array}{l}\text { Entre os mais jovens, há uma tendência de identificação com o termo black } \\
\text { disposto pela moda e pela música, levando-os a se autoidentificarem como } \\
\text { negros. }\end{array}$ \\
\hline Lugar & $\begin{array}{l}\text { Correspondem ao mercado de trabalho, o mercado do matrimônio e da paquera e } \\
\text { a relação com a polícia. Nesses espaços, o negro sofre maior discriminação, } \\
\text { porque são espaços hegemonicamente brancos e onde a competição, a estética e } \\
\text { o status deixam os negros em desvantagem. }\end{array}$ \\
\cline { 2 - 4 } & $\begin{array}{l}\text { Aqui a situação se atenua porque há mais negros, e isso tende a não ser um fator } \\
\text { de surpresa, tampouco envolve a competição por status e poder. Trata-se dos } \\
\text { espaços no domínio do lazer, como o botequim, o dominó, a torcida, a seresta, o } \\
\text { forró, o papo com os vizinhos na esquina, etc. São espaços onde ser negro não é } \\
\text { um obstáculo. }\end{array}$ \\
\hline $\begin{array}{l}\text { Espaços } \\
\text { negros }\end{array}$ & $\begin{array}{l}\text { Este lugar inverte a lógica das áreas duras. Aqui ser negro é uma vantagem. São } \\
\text { o bloco afro, a batucada, os terreiros de umbanda e candomblé, as rodas de } \\
\text { pagode e de samba, os grupos carnavalescos, a capoeira e etc. Lugares onde a } \\
\text { cultura negra é a base das atividades que são desenvolvidas. }\end{array}$ \\
\hline
\end{tabular}

Nota. Fonte: Adaptado de Sansone, L. (1996). Nem somente preto ou negro: o sistema de classificação racial no Brasil que muda. Afro-Ásia, 18(2), 165-187.

Os resultados apresentados por Sansone (1996) nos mostram que a marca, elaborada por Nogueira (2007), não se restringe apenas à aparência do sujeito, pois as percepções de cor variam de acordo com a posição desse sujeito, do lugar em que ele se encontra e do momento em que ele se coloca. Assim, temos no Brasil um tipo de classificação racial bastante dinâmico e difícil de ser visto e analisado a partir de um ponto fixo. Ser negro no Brasil, depende sempre de um conjunto de fatores e vai bem além da simples aparência física, mesmo que esta seja bastante nítida, como no caso dos negros retintos.

Quando confrontamos esses fatores com os paradigmas apresentados anteriormente, podemos notar a força do paradigma na morenidade, e a forma como sua ambiguidade é explorada para lidar com as diversas situações que permeiam as relações raciais no Brasil. Deste modo, o chamado mito da democracia racial se apresenta como um elemento estruturante nas percepções sobre raça e racismo, o que pode ser um problema quando pensamos na raça como tema político. Ou seja, a ambiguidade da categoria moreno opera um disfarce nas diferenças raciais e acaba sendo um ponto de fuga da própria condição racial, enfraquecendo a identidade negra. Segundo Sansone (1996), para os ativistas negros, trata-se de uma abordagem desfavorável à luta antirracista, pois o fortalecimento da autoestima negra e a mobilização política dependem de linhas raciais claras que definam o mundo dos negros em contraste ao dos brancos, o que para Nogueira (2007) remete ao movimento político que essa separação inspira, criando uma minoria nacional coesa.

Por outro lado, ao mostrar que a atmosfera do lugar altera a percepção das pessoas sobre as relações raciais, a noção de áreas duras nos mostra um lugar onde o recorte racial é claro e a discriminação opera com toda a sua força. O que em certa medida confirma os resultados do paradigma da desigualdade racial, em que as desigualdades sociais são influenciadas por práticas discriminatórias e mecanismos racistas que prejudicam a competição dos negros com os brancos. Por essa razão, uma das estratégias de mobilização dos movimentos negros consta em generalizar as áreas duras como sendo a realidade do negro no Brasil, quando, na verdade, ela convive com outros espaços mais flexíveis de relações raciais, conforme mostram as dinâmicas das áreas moles e do espaço negro. Assim, quando falamos em relações raciais no Brasil, há que se considerar, além das diferenças 
apontadas por Nogueira (2007), o caráter contingencial das convenções locais apontadas por Sansone (1996) que, segundo ele próprio, "se associam [às] influências crescentes que resultam do processo de globalização das culturas e identidades étnicas" (p. 186). O que nos coloca, enquanto pesquisadores, diante de um contexto mutável e complexo que ainda carece de muitas pesquisas empíricas para compreendê-lo melhor.

\section{Discussão: Possíveis Contribuições Para os Estudos Organizacionais no Brasil}

Antes de explorar as contribuições para o estudo das organizações no Brasil, é preciso desnaturalizar o que sabemos sobre gestão e organização para pensá-las a partir do nosso próprio contexto, ou seja, a partir do Sul Global (Alcadipani \& Rosa, 2011). Isso significa que: (a) os EUA não são a única fonte de saberes úteis para análise organizacional; que (b) as organizações não são sinônimo de corporação (mercado), pois estão presentes também no âmbito do Estado (organizações públicas) e da sociedade civil (organizações sociais); e que, (c) apesar dos desenhos globais serem muito mais influentes no mundo contemporâneo, existem histórias locais que também influenciam a gestão e a organização no Brasil.

Isso posto, podemos agora pensar as organizações como um microcosmo social, que reproduz uma série de fenômenos que tradicionalmente estiveram presentes na sociedade brasileira, entre os quais as relações raciais. Ademais, como ressalta Prestes Motta (2000), as organizações brasileiras se articulam com um sistema de relações típico da cultura brasileira, em que a distância social convive com a proximidade física, o que torna as relações sociais ambíguas e mais complexas à medida que envolve laços de afetividade e do bom convívio entre os grupos. Com efeito, ao pensarmos as relações raciais nas organizações brasileiras, estamos pensando espaços que reproduzem relações raciais de forma distinta das organizações norte-americanas, que podem assumir a ambiguidade inerente tanto à dinâmica das áreas duras, como à das áreas moles e à dos espaços negros. Que pode ser composta por uma força de trabalho mais jovem ou mais velha, cuja percepção pode estar mais ou menos alinhada à dinâmica da democracia racial ou da desigualdade racial. Ou ainda, que dependendo do status de ser gerente, supervisor ou operário, podem ter diferentes formas de lidar com o preconceito e a discriminação entre níveis de gestão e entre grupos de trabalhadores, de acordo com a importância de um ou outro setor da organização. Ademais, essa diferença de status pode levar executivos e funcionários a se autodeclararem de forma diversa nos censos demográficos, distorcendo sua própria condição racial.

Considerando a visão desnaturalizada e os fatores contingenciais apresentados por Sansone (1996), os estudos organizacionais brasileiros podem fazer uma releitura de temas como, por exemplo, os traços da cultura brasileira e a questão da valorização do estrangeiro nas organizações (Prestes Motta, Alcadipani, \& Bresler, 2001) ou mesmo a receptividade cordial desses estrangeiros no país (Oliveira \& Martins, 2009). Como fica a questão do estrangeiro se ele for um americano ou um europeu negro? Terá o mesmo status e o mesmo tratamento que um branco? Como fica a cordialidade neste caso?

No campo dos estudos sobre relações de trabalho nas organizações, o debate acerca das relações raciais pode ajudar, por exemplo, a compreender outros aspectos presentes na organização da classe trabalhadora (Ferraz \& Barreto, 2012), na reprodução da violência simbólica (Rosa \& Brito, 2009), e na dinâmica das equipes de trabalhadores e suas redes de apoio e solidariedade (Weber \& Grisci, 2013). Como a questão racial se articula a consciência de classe no movimento de trabalhadores? Quais os mecanismos simbólicos de segregação vertical e horizontal dos negros no local de trabalho? Como equipes multirraciais se articulam para criação de vínculos interpessoais? A solidariedade dos grupos resiste às diferenças raciais ou se ajustam a elas de acordo com os laços afetivos?

Em relação aos espaços organizados, os estudos podem se voltar para análise das relações raciais em organizações típicas das áreas duras, como as corporações de mercado e as organizações 
públicas. Espaços típicos de competição individual e organizacional que tende, por exemplo, a rejeitar questões ligadas à inclusão social por meio de cotas para grupos especiais (M. A. Ribeiro \& Carneiro, 2009). Nas áreas moles, como bares, clubes, e associações recreativas, a ênfase no diálogo com as relações raciais pode contribuir para captar aspectos sutis de como a cultura organizacional é incorporada fora das áreas duras e permeada pela descontração e informalidade das relações (FloresPereira, Davel, \& Cavedon, 2008). Finalmente, os espaços negros, como escolas de samba, clubes de futebol e organizações populares podem ser analisados como paradigma alternativo de mescla cultural e de igualdade racial, ou mesmo de ruptura com dicotomias clássicas, tais como as noções de preto e branco nas organizações (Tureta \& Araújo, 2013).

Em cada um desses espaços de relações raciais é possível coletar e analisar histórias locais, contrapondo-as aos desenhos globais estruturados a partir de políticas de diversidade inspiradas na ação afirmativa ou na igualdade no emprego. Ao confrontar o local e o global, os estudos podem contribuir para uma reflexão crítica sobre a efetividade de tais políticas nas organizações brasileiras, podendo rejeitá-las ou mesmo aperfeiçoá-las para melhor servir a nossa realidade organizacional. Apesar dos benefícios em termos de inclusão racial, vale lembrar que as ações afirmativas não são soluções brasileiras e que a sua exportação para outros contextos raciais não está totalmente livre de problemas, conforme apontam alguns estudos críticos sobre suas consequências para as relações raciais dentro (Andrews, 1997) e fora (Sowell, 2005) dos EUA.

Ao problematizar as políticas de diversidade gestadas em países anglo-saxões, estamos problematizando também o que está por detrás dessas políticas, que é todo um contexto cultural, político, histórico e organizacional das sociedades em que foram formuladas. Por conseguinte, parece correto supormos que haja certa dissonância quando tentamos pensar nossas organizações com base em modelos de sociedade diferentes da nossa. Não se trata de afirmar alguma singularidade ou excepcionalidade do caso brasileiro, pois já vimos que isso foi desmascarado pelo projeto Unesco nos anos 1950, mas de considerar que as organizações brasileiras, apesar de ainda hoje serem dependentes das práticas e do conhecimento em gestão, e organização do Norte Global, podem (e devem) ser pensadas de maneira específica, lançando mão do conhecimento produzido durante décadas por nossos sociólogos e antropólogos, mas que, com algumas exceções (Ex. Prestes Motta \& Caldas, 1997), estiveram fora da reflexão sobre organizações no Brasil. Assim, ao se debruçar sobre o fenômeno das relações raciais - que é apenas um dos muitos fenômenos sociais que se reproduzem nas organizações - abrimos um precedente que nos leva a cruzar fronteiras disciplinares e a pensar as organizações de forma ampliada e ao mesmo tempo reduzida aos nossos interesses particulares de desvendar sua dinâmica e de compreender como elas funcionam.

Por fim, já que estamos falando em relações raciais, não posso deixar de refletir sobre as implicações de uma academia de Administração em que a presença de pesquisadores negros é notoriamente baixa. Que tipo de espaço estamos reproduzindo na universidade que torna a academia tão branca diante de uma sociedade tão colorida? Trata-se de uma das áreas duras das relações raciais? Não pesquisamos as relações raciais nas organizações porque acreditamos serem espaços racialmente neutros ou esses espaços são vistos como racialmente neutros porque não são pesquisados? Penso que essas questões também devem ser objeto de reflexão sobre a diversidade na organização do nosso próprio espaço acadêmico.

\section{Considerações Finais}

Neste trabalho, a proposta era de cumprir dois objetivos: problematizar os estudos sobre diversidade e recuperar o debate brasileiro sobre relações raciais. Ambos se desenrolaram no decorrer da primeira e da segunda parte do trabalho, quando é mostrado que os estudos sobre diversidade surgiram como resposta às demandas de inclusão social em países como os EUA, cuja estrutura social difere da nossa em virtude de uma formação histórica marcada pela diferenciação entre grupos que coexistem preservando suas especificidades culturais. Em seguida, mostra-se que em países como o 
Brasil prevaleceu a lógica da assimilação dos grupos minoritários em virtude de sucessivos processos de miscigenação típicos da nossa formação histórica e que, justamente por isso, deram margem a interpretações utópicas de uma sociedade livre de tensões e conflitos raciais.

Essas duas proposições nos ajudam a perceber que os estudos organizacionais no Brasil têm se colocado de maneira deslocada nesse debate, seja pela suposição de que nossa gestão da diversidade deve seguir parâmetros anglo-saxões, seja pelo distanciamento que a área tem mantido dos estudos brasileiros que abordam minorias raciais e sua dinâmica de relações. Sendo assim, o contexto sociohistórico brasileiro emerge como elemento fundamental para se compreender as relações raciais nas organizações, pois é nele que o sujeito mestiço articula as duas pontas do debate brasileiro. Se de um lado a democracia racial se faz a partir dos processos de miscigenação que produzem o sujeito mestiço, aquele moreno que flutua em diversos espaços de relações como possibilidade de convivência harmônica entre as diferentes raças, de outro, este mesmo mestiço é aquele que mascara os processos de exclusão racial nas organizações em virtude de sua capacidade de agregar amplo gradiente de cores que é ativado de maneira contingencial, ofuscando os mecanismos sutis que geram desigualdades raciais nos diferentes espaços de relações. Com efeito, essas peculiaridades ajudam a direcionar nossas escolhas teóricas e metodológicas para o estudo da relações raciais em organizações brasileiras, pois o nosso campo de estudos já dispõe de uma produção científica bastante diversificada que poderia dialogar com os estudos brasileiros, gerando novos insights sobre a questão racial no Brasil.

Portanto, mais do que uma opção teórica e/ou metodológica, o esforço de contextualização dos estudos sobre diversidade nas organizações surge como uma necessidade histórica para que possamos compreender a forma com que as pessoas se veem, se assumem e se colocam nas relações do cotidiano. Apesar de esse debate ainda não ocupar o espaço que merece no âmbito dos estudos organizacionais brasileiros, espera-se que este ensaio seja um convite para muitos outros. Afinal, a diversidade de ideias continua sendo o melhor caminho para se compreender a diversidade do mundo.

\section{Referências}

Agócs, C., \& Burr, C. (1996). Employment equity, affirmative action and managing diversity: assessing the differences. International Journal of Manpower, 17(4/5), 30-45. doi: $10.1108 / 01437729610127668$

Alberti, V., \& Pereira, A. (2006). A defesa das cotas como estratégia política do movimento negro contemporâneo. Estudos Históricos, 1(37), 143-166.

Alcadipani, R., \& Rosa, A. R. (2011). From grobal management to glocal management: Latin American perspectives as a counter dominant management epistemology. Canadian Journal of the Administrative Sciences, 28(4), 453-466. doi: 10.1002/cjas.165

Alves, M. A., \& Galeão-Silva, L. (2004). A crítica da gestão da diversidade nas organizações. Revista de Administração de Empresas, 44(3), 20-29. doi: 10.1590/S0034-75902004000300003

Andrews, G. (1997). Ação afirmativa: um modelo para o Brasil? In J. Souza (Org.), Multiculturalismo e racismo: uma comparação Brasil-Estados Unidos (pp. 137-144). Brasília: Paralelo 15.

Banton, M. (1979). A idéia de raça. Lisboa: Ed. 70.

Bastide, R., \& Fernandes, F. (1955). Relações raciais entre negros e brancos em São Paulo. São Paulo: Anhembi.

Butler, J. (1996). An affirmative view. Representations, (55), 74-83. doi: 10.2307/3043737 
Conceição, E. B. (2009, setembro). A negação da raça nos estudos organizacionais. Anais do Encontro Nacional da Associação Nacional de Pós-Graduação e Pesquisa em Administração, São Paulo, SP, Brasil, 33.

Costa, S., \& Ferreira, C. (2006, junho). Diversidade e minorias nos estudos organizacionais brasileiros: presença e lacunas na última década. Anais do Encontro de Estudos Organizacionais, Porto Alegre, RS, Brasil, 4.

Cox, T., Jr. (1991). The multicultural organization. Academy of Management Executive, 5(2), 34-47.

Cox, T., Jr. (1993). Cultural diversity in organizations: theory resource \& practice. San Francisco: Berret-Koehler.

Cox, T., Jr., \& Blake, S. (1991). Managing cultural diversity: implication for organizational competitiveness. Academy of Management Executive, 5(2), 45-56.

Cox, T., Jr., \& Nkomo, S. (1990). Invisible men and women: a report on race as a variable in organization behavior. Journal of Organizational Behavior, 11(6), 419-431. doi: 10.1002/job.4030110604

Degler, C. (1976). Nem preto, nem branco: escravidão e relações raciais no Brasil e nos Estados Unidos. Rio de Janeiro: Labor do Livro.

Domingues, P. (2007). Movimento negro brasileiro: alguns apontamentos históricos. Tempo, 12(23), 100-122. doi: 10.1590/S1413-77042007000200007

Eco, U. (1983). Como se faz uma tese. São Paulo: Perspectiva.

Fernandes, F. (1965). A integração do negro na sociedade de classes. São Paulo: Editora Nacional.

Ferraz, D., \& Barreto, J. (2012). A organização dos trabalhadores desempregados como mediação para a consciência de classe. Organizações \& Sociedade, 19(61), 187-207. doi: 10.1590/S198492302012000200002

Flores-Pereira, M. T., Davel, E., \& Cavedon, N. R. (2008). Drinking beer and understanding organizational culture embodiment. Human Relations, 61(7), 1007-1026. doi: $10.1177 / 0018726708093906$

Freyre, G. (2006). Casa grande \& senzala (54th ed.). São Paulo: Global. (Obra original publicada em 1933)

Gilbert, J. A., Stead, B. A., \& Ivancevich, J. M. (1999). Diversity management: a new organizational paradigm. Journal of Business Ethics, 21(1), 61-76. doi: 10.1023/A:1005907602028

Gilroy, P. (1993). The black Atlantic: modernity and double consciousness. Cambridge: Harvard University Press.

Gonçalves, B. (Org.). (2006). O compromisso das empresas com a promoção da igualdade racial. São Paulo: Ethos.

Guimarães, A. S. (1999). Racismo e anti-racismo no Brasil. São Paulo: Ed.34.

Hall, S. (1999). A identidade cultural na pós-modernidade. Rio de Janeiro: DP\&A.

Hall, S. (2000). The multi-cultural question. In B. Hesse (Ed.), Un/settled multiculturalism. London: Zed Books. 
Hanashiro, D. M. M., \& Carvalho, S. G. de (2005). Diversidade cultural: panorama atual e reflexões para a realidade brasileira. Revista Eletrônica de Administração, 11(5), 1-21. Recuperado de file://C:/Users/RAC/Downloads/40623-161231-1-PB.pdf

Hartmann, D., \& Gerteis, J. (2005). Dealing with diversity: mapping multiculturalism in sociological terms. Sociological Theory, 23(2), 218-240. doi: 10.1111/j.0735-2751.2005.00251.x

Hasenbalg, C. (1995). Discriminação e desigualdades raciais no Brasil (2a ed.). Belo Horizonte: UFMG; Rio de Janeiro: IUPERJ. (Obra original publicada em 1979)

Hofbauer, A. (2006). Uma história de branqueamento ou o negro em questão. São Paulo: Unesp.

Hollinger, D. (2003). Amalgamation and hypodescent: the question of ethnoracial mixture in the history of the United States. The American Historical Review, 108(5), 1363-1390. doi: $10.1086 / 529971$

Instituto Ethos. (2010a). Como as empresas podem (e devem) valorizar a diversidade. São Paulo: Autor.

Instituto Ethos. (2010b). Perfil social, racial e de gênero das 500 maiores empresas do Brasil e suas ações afirmativas - pesquisa 2010. São Paulo: Autor.

Jaccoud, L., \& Beghin, N. (2002). Desigualdades raciais no Brasil: um balanço da intervenção governamental. Brasília: Ipea.

Kalev, A., Kelly, E., \& Dobbin, F. (2006). Best practices or best guesses? Assessing the efficacy of corporate affirmative action and diversity policies. American Sociological Review, 71(4), 589617. doi: $10.1177 / 000312240607100404$

Kymlicka, W. (1998). American multiculturalism on the international arena. Dissent, 1(3), 12-18. doi: 10.1093/0199240981.003.0015

Lacerda, J. B. (1912). O Congresso universal das raças reunido em Londres. Rio de Janeiro: Papelaria Macedo.

Leite, M. L. M. (1995). Naturalistas viajantes. História, Ciências, Saúde-Manguinhos, 1(2), 7-19. doi: $10.1590 / \mathrm{S} 0104-59701995000100002$

Maio, M. C. (1993). Negros e Judeus no Rio de Janeiro: um ensaio de movimento pelos direitos civis. Estudos Afro-Asiáticos, 1(25), 161-188.

Maio, M. C. (1999). O projeto Unesco e a agenda das ciências sociais no Brasil dos anos 40 e 50. Revista Brasileira de Ciências Sociais, 14(41), 141-158. doi: 10.1590/S010269091999000300009

Morris, A. D. (1984). The origins of the civil rights movement: black communities organizing for change. New York: Free Press.

Morris, A. D. (1999). A retrospective on the civil rights movement: political and intellectual landmarks. Annual Review of Sociology, 25, 517-539. doi: 10.1146/annurev.soc.25.1.517

Motta, R. (2000). Paradigmas de interpretação das relações raciais no Brasil. Estudos Afro-Asiáticos, (38), 113-133. doi: 10.1590/S0101-546X2000000200006

Myers, A. (2003). O valor da diversidade racial nas empresas. Estudos Afro-Asiáticos, 25(3), 483-515. doi: 10.1590/S0101-546X2003000300005

Nina Rodrigues, R. (1935). Os africanos no Brasil. São Paulo: Editora Nacional. 
Nkomo, S. (1992). The emperor has no clothes: rewriting "race in organizations". Academy of Management Review, 17(3), 487-513. doi: 10.5465/AMR.1992.4281

Nkomo, S. (2009). The sociology of race: the contributions of W.E.B. Du Bois. In P. Adler (Eds.), The Oxford handbook of sociology and organization studies: classical foundations (pp. 375-398). Oxford: Oxford University Press.

Nogueira, O. (2007). Preconceito racial de marca e preconceito racial de origem: sugestão de um quadro de referência para a interpretação do material sobre relações raciais no Brasil. Tempo Social, 19(1), 287-308. doi: 10.1590/S0103-20702007000100015

Oliveira, C. F. de, \& Martins, P. M. (2009). A hospitalidade e cordialidade brasileira: o Brasil percebido por estrangeiros. Turismo em Análise, 20(2), 196-209. doi: 10.11606/issn.19844867.v20i2p196-209

Ortiz, R. (1985). Cultura brasileira e identidade nacional. São Paulo: Brasiliense.

Prestes Motta, F. (2000). Organizações e sociedade: a cultura brasileira. Organização \& Sociedade, 7(19), 13-17.

Prestes Motta, F., Alcadipani, R., \& Bresler, R. (2001). A valorização do estrangeiro como segregação nas organizações. Revista de Administração Contemporânea [Edição Especial], 5, 19-33. doi: 10.1590/S1415-65552001000500004

Prestes Motta, F., \& Caldas, M. (Orgs.). (1997). Cultura organizacional e cultura brasileira. São Paulo: Atlas.

Quijano, A. (2000). Coloniality of power, ethnocentrism, and Latin America. Nepantla, 1(3), 553-580.

Ribeiro, D. (1995). O povo brasileiro. São Paulo: Companhia das Letras.

Ribeiro, M. A., \& Carneiro, R. (2009). A inclusão indesejada: as empresas brasileiras face à lei de cotas para pessoas com deficiência no mercado de trabalho. Organizações \& Sociedade, 16(50), 545-564.

Rocha, A. (2009). Abolicionistas brasileiros e ingleses: a coligação entre Joaquim Nabuco e a British and Foreign Anti-Slavery Society (1880-1902). São Paulo: Unesp.

Rosa, A. R., \& Brito, M. J. (2009). Ensaio sobre violência simbólica nas organizações. Organizações \& Sociedade, 16(51), 629-646.

Sansone, L. (1996). Nem somente preto ou negro: o sistema de classificação racial no Brasil que muda. Afro-Ásia, 18(2), 165-187.

Santos, H. (2001). A busca de um caminho para o Brasil. São Paulo: Senac.

São Paulo, E. de (2010). Preliminary studies on affirmative action in a Brazilian university. Revista de Administração Mackenzie, 11(3), 27-45. doi: 10.1590/S1678-69712010000300004

Saraiva, L. A. S., \& Irigaray, H. A. R. dos (2009). Políticas de diversidade nas organizações: uma questão de discurso? Revista de Administração de Empresas, 49(3), 337-348. doi: 10.1590/S0034-75902009000300008

Schwarcz, L. (1993). O espetáculo das raças: cientistas, instituições e questão racial no Brasil. São Paulo: Companhia das Letras.

Skidmore, T. (1989). Preto no branco: raça e nacionalidade no pensamento brasileiro. São Paulo: Paz e Terra. 
Sowell, T. (2005). Affirmative action around the world: an empirical study. New Heaven: Yale University Press.

Szmerecsányi, T. (1985). Elementos para uma história social da produção científica no Brasil. Caderno de Difusão Tecnológica, 2(1), 165-70.

Taylor, C. (1994). The politics of recognition. In C. Taylor (Ed.), Multiculturalism: examining the politics of recognition (pp. 25-74). New Jersey: Princeton University Press.

Thomas, D., \& Ely, R. (1996). Making differences matter: a new paradigm for managing diversity. Harvard. Business Review, 74(5), 107-118.

Thomas, R. (1990). From affirmative action to affirmative diversity. Harvard Business Review, 68(2), 107-118.

Tureta, C., \& Araujo, B. F. V. B. de (2013). Escolas de samba: trajetória, contradições e contribuições para os estudos organizacionais. Organizações \& Sociedade, 20(64), 111-129. doi: 10.1590/S1984-92302013000100008

Vieira, M., \& Caldas, M. (2005). Teoria crítica e pós-modernismo: principais alternativas à hegemonia funcionalista. Revista de Administração de Empresas, 46(1), 59-70. doi: 10.1590/S003475902006000100006

Walters, R. (1995). O princípio da ação afirmativa e o progresso racial nos Estados Unidos. Estudos Afro-Asiáticos, 28(3), 129-140.

Weber, L., \& Grisci, C. L. I. (2013). Conexões entre trabalhadores: alternativas para além do discurso hegemônico de grupos e equipes. Organizações \& Sociedade, 20(65), 207-224. doi: $10.1590 /$ S1984-92302013000200002

Zanoni, P., Janssens, M., Benschop, Y., \& Nkomo, S. (2010). Unpacking diversity, grasping inequality: rethinking difference through critical perspectives. Organization, 17(1), 9-19. doi: $10.1177 / 1350508409350344$ 